\title{
Lagrangian model using CFD flow data to predict the current- voltage characteristics of a solid oxide fuel cell repeat unit
}

\author{
C Meier', D Meier², F Vandercruysse', T Hocker* \\ 1. HEXIS AG, Winterthur, Switzerland \\ 2. Zurich Uni of Appl. Sciences, Inst. of Comp. Physics, \\ Winterthur, Switzerland
}

\begin{abstract}
A model framework is presented to predict the current-voltage $(I-U)$ characteristics and hence the electrical performance of a solid oxide fuel cell (SOFC) repeat unit, i.e., a planar SOFC with adjacent current collector plates. The model uses as input residence times obtained from 3D CFD data for the fuel flowing through the anodic gas channels of a current collector plate. These residence times are then used by an electrochemical model to predict the fuel conversion along different flow paths for various electrical loads. This way, the overall $(I-U)$ behaviour of the repeat unit follows from combining the fuel conversion rates (and respective electrical currents) for the individual flow paths. Since we use a Lagrangian reference frame for the electrochemical model, for a given electrical load, only a simple timeintegration of a first-order ODE is required. Therefore, this modelling approach is very efficient and well suited for extensive parameter studies, e. g., to optimise the fuel residence times with respect to the electrical performance of the repeat unit. To ensure its reliability, the model has been validated by comparison with both experimental data and other (I-U) models.
\end{abstract}

\section{INTRODUCTION}

Here, we present a simple yet powerful model to predict the current-voltage (I-U) characteristics of a repeat unit of a planar solid oxide fuel cell (SOFC) stack. Knowledge of U (I) - either from experiments or model calculations - allows one to assess the electrical performance $\mathrm{P}=\mathrm{U}$ I of the considered SOFC repeat unit under different operation conditions and hence represents its fingerprint. Therefore, (I-U) data is useful to assess both the initial startup performance as well tracking the performance over longer periods of operation [Kendall 2016]. As shown in Fig. 1, a SOFC stack is an assembly of several repeat units, that is, solid oxide fuel cells with adjacent current collector plates arranged in series. The current collectors have to fulfil two main tasks: (i) collecting the electrical current from the anode side of one cell and delivering it to the cathode side of the next cell and (ii) distributing the fuel on the anode side and the air on the cathode side over the whole cell. The electrical performance of a planar SOFC stack depends on a large number of influencing parameters including socalled internal resistances such as various ohmic losses and the kinetics of the involved

*Corresponding Author: thomas.hocker@zhaw.ch 
electrochemical and reforming reactions as well as on the local supply of each cell with fuel and air. The latter is influenced by the design of the current collector: it typically consists of a rather complex arrangement of flow channels for gas distribution and ribs for current collection and current distribution.

For optimising the current collector design it is highly relevant to assess the impact of the fuel and oxygen flow patterns on the resulting electrochemical performance. In principle, this can be done both experimentally and by computer models. As experimental approach, segmented repeat units have been employed to spatially resolve

e. g. local electrical currents. However, this requires a delicate, elaborated experimental setup [Schulze 2007, Wuillemin 2009, Bessler 2010]. Concerning theoretical approaches, FEor CFD-models are usually used either in full 3D or in 2+1D configurations [Janardhanan 2006, Schumacher 2012, Sang-Keun 2016]. Even though they allow one to incorporate a large number of physicochemical phenomena, they often suffer from costly implementations, convergence issues and numerical errors. Also, they are often CPU-intensive which limits their applicability to extensive parameter studies. As will be explained in the following section our model approach overcomes these drawbacks while still keeping essential features of a fuel cell systems.

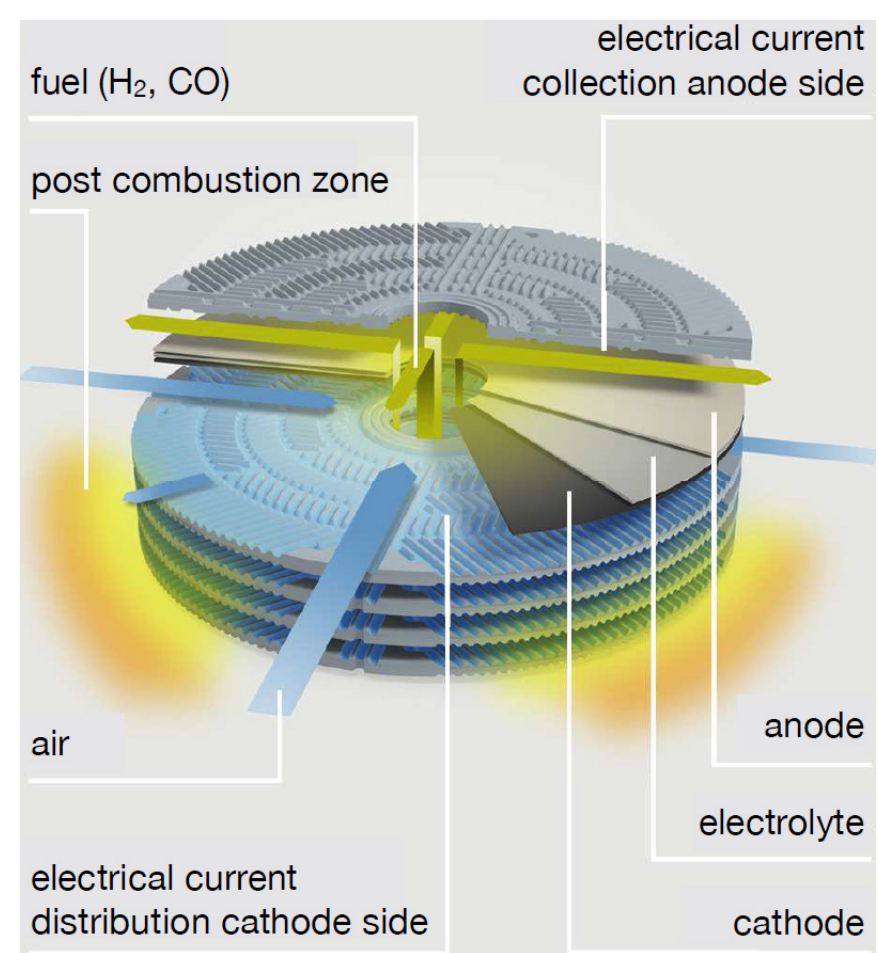

Figure 1: Design of the HEXIS SOFC stack, i.e., a disc-shaped solid oxide fuel cells with adjacent current collector plates arranged in series [Mai 2013]. 


\section{MODEL}

\subsection{General approach}

To optimize the design of SOFC current collector plates, a modelling approach would be desirable that is yet fast, robust and simple to use, but still incorporates the impact of the complex gas flow pattern on the local gas compositions and current densities. For this, we pursue an approach that is based on the following steps:

1. Assess the flow pattern of the fuel distributed over the anode side of a SOFC repeat unit by calculating the corresponding residence-time-distribution (RTD) from 3D gas flow CFD data

2. Assess the electrochemical performance for each residence time (representing the corresponding flow paths through the repeat unit) by an electrochemical model that is based on a Lagrangian reference frame

3. Determine the overall current-voltage behavior of the repeat unit by combining the results from 2.

\subsection{Model assumptions}

The model is based on a number of assumptions. Some of them are specific to the cell and current collector design of the HEXIS SOFC stack [Mai 2013]. Hence, they might not or only partially hold for other SOFC stack designs. The main assumptions are as follows:

\subsubsection{Constant oxygen concentration on cathode side}

Variations in the oxygen concentration on the cathode side are neglected. This implies an excess of air fed to the cathode which often is a reasonable assumption. However, the consumption of oxygen could be included as an extension to the presented model.

\subsubsection{Steady-state operation}

Transient effects are neglected, i.e., the SOFC repeat unit runs in steady-state mode. Since SOFCs usually are developed for stationary applications, this is a valid assumption. However, transient effects could be included as an extension to the presented model, e. g., to calculate the gas conversion impedance at different fuel utilizations.

\subsubsection{Constant operating temperature}

The temperature is assumed to be constant over the whole repeat unit. To our experience, this is a valid assumption for rather thick current collector plates made from metals with rather high thermal conductivities. To release this assumption, an additional energy balance would have to be solved.

\subsubsection{Constant overall pressure and molar density}

Fuel flow velocities along the gas channels of current collector plates usually are so small that the corresponding pressure drop between inlet and outlet is well below $100 \mathrm{~Pa}$. In addition, as mentioned above, the variation in fuel gas temperatures is small - provided the current collector plate is a good thermal conductor. According to the ideal gas law for the fuel gas 
mixture, $\mathrm{p}=\mathrm{c} \mathrm{R} \mathrm{T}$, where $\mathrm{c}=\mathrm{n} / \mathrm{V}$ is the molar density in $\mathrm{mol} / \mathrm{m}^{3}$ and $\mathrm{R}=8.314 \mathrm{~J} /(\mathrm{mol} \mathrm{K})$, constant $\mathrm{p}$ and $\mathrm{T}$ implies the molar overall density $\mathrm{c}$ to be constant as well.

\subsubsection{Gas transport only by convection}

Gas diffusion (i.e. dispersion) within the current collector flow channels is neglected. Hence it is assumed that species transport by convection is dominating over that by diffusion.

\subsubsection{Total internal resistance $A_{S R}$ independent of current}

It is assumed that the total area-specific internal resistance of the repeat unit, $\operatorname{ASR}_{\mathrm{RU}}$ in $\Omega \mathrm{m}^{2}$, is independent of the (local and hence overall) electrical current density $j_{\mathrm{el}}$ in $\mathrm{A} / \mathrm{m}^{2}$. This implies that either the sum of the various ohmic losses dominates over the polarisation losses of the involved electrochemical reactions, and/or the polarization losses depend linearly on the electrical current, i.e., they are within the small overpotential, linear regime of the ButlerVolmer equation. This assumption is certainly not true for fuel cells in general, but, based on EIS-measurements, was found to be valid for the HEXIS SOFC stack, see Fig. 8 in [Linder 2015].

\subsubsection{Spatially uniform external load $\mathrm{U}_{\mathrm{L}}$}

It is assumed that the local voltage over a SOFC repeat unit can be approximated by $\mathrm{U}_{\mathrm{L}}=\mathrm{U}_{\mathrm{N}}-\mathrm{ASR}_{\mathrm{RU}} \mathrm{j}_{\mathrm{el}}$, where $\mathrm{U}_{\mathrm{L}}$ represents the applied external load and $\mathrm{U}_{\mathrm{N}}$ is the Nernst or open circuit voltage [Linder 2011]. $\mathrm{U}_{\mathrm{L}}$ is assumed to be uniform over the whole repeat unit. This implies the electrical conductivity of the current collector to be sufficiently large, so that in-plane voltage drops can be neglected. Again, this is a valid assumption for current collectors made from metals which exhibit high electrical conductivities.

\subsubsection{All hydrocarbon fuels converted to $\mathrm{H}_{2}, \mathrm{H}_{2} \mathrm{O}, \mathrm{CO}, \mathrm{CO}_{2}$}

Concerning the electrochemical fuel conversion, we assume that through re- forming reactions with $\mathrm{O}_{2}$ and/or $\mathrm{H}_{2} \mathrm{O}$, hydrocarbon fuels such as $\mathrm{CH}_{4}, \mathrm{C}_{2} \mathrm{H}_{6}$, and $\mathrm{C}_{3} \mathrm{H}_{8}$ all are converted to $\mathrm{H}_{2}$, $\mathrm{H}_{2} \mathrm{O}, \mathrm{CO}$ and $\mathrm{CO}_{2}$. Furthermore, we assume that the electrochemical conversion of $\mathrm{H}_{2}$ to $\mathrm{H}_{2} \mathrm{O}$ is much faster than that of $\mathrm{CO}$ to $\mathrm{CO}_{2}$. This implies that $\mathrm{CO}$ gets oxidized only by the watergas shift reaction $\mathrm{CO}+\mathrm{H}_{2} \mathrm{O} \rightleftharpoons \mathrm{H}_{2}+\mathrm{CO}_{2}$ and $\mathrm{H}_{2}$ gets electrochemically converted only through the water formation reaction $\mathrm{H}_{2}+1 / 2 \mathrm{O}_{2} \rightarrow \mathrm{H}_{2} \mathrm{O}$. While not obvious, these assumptions seem to be reasonable for the HEXIS SOFC stack running on natural gas mixtures [Linder 2011, Linder 2015].

\subsubsection{Local chemical equilibrium}

In addition to the assumption that all hydrocarbon fuels are converted to $\mathrm{H}_{2}, \mathrm{H}_{2} \mathrm{O}, \mathrm{CO}$ and $\mathrm{CO}_{2}$, we assume local chemical equilibrium apart from the electrochemical conversion $\mathrm{H}_{2}+1 / 2 \mathrm{O}_{2} \rightarrow \mathrm{H}_{2} \mathrm{O}$ which is driven by the potential difference $\mathrm{U}_{\mathrm{N}}-\mathrm{U}_{\mathrm{L}}>0$.

\subsection{Electrochemical model}

As pointed out above, at least for the HEXIS SOFC stack, it seems to be reasonable to assume that all gaseous hydrocarbon fuels are converted through reforming reactions to $\mathrm{H}_{2}$ and $\mathrm{CO}$, while the latter is further converted via the water-gas shift reaction to $\mathrm{H}_{2}$ and $\mathrm{CO}_{2}$. Hence, the only electrochemical conversion that needs to be considered is the water formation reaction 


$$
\left.\mathrm{H}_{2}\right|_{\text {anod }}+\left.\left.\frac{1}{2} \mathrm{O}_{2}\right|_{\text {cath }} \rightarrow \mathrm{H}_{2} \mathrm{O}\right|_{\text {anod }}
$$

Since $\mathrm{H}_{2}$ is converted electrochemically, the oxygen is provided by the cathode, where it is reduced to $\mathrm{O}^{2-}$ ions. These $\mathrm{O}^{2-}$ ions then travel through the electrolyte and recombine at the anode with $2 \mathrm{H}^{+}$to form $\mathrm{H}_{2} \mathrm{O}$. Here, assume that the impact of the complete electrochemical conversion with respect to the anode side gas phase is completely governed by the equimolar conversion $\left.\left.\mathrm{H}_{2}\right|_{\text {anod }} \rightarrow \mathrm{H}_{2} \mathrm{O}\right|_{\text {anod. }}$. Hence, this conversion can be tracked by the steady-state elemental balance for gaseous oxygen along an anode side streamline, i.e.

$$
\frac{\partial\left(\mathrm{c}_{\mathrm{O}} \mathrm{w}_{\mathrm{i}}\right)}{\partial \mathrm{x}_{\mathrm{i}}}=\mathrm{S}_{\mathrm{O}}
$$

Here, $\mathrm{w}_{\mathrm{i}}$ denotes the local fluid velocity in Einstein notation, $\mathrm{c}_{\mathrm{O}}$ is the gas phase $\mathrm{O}$ concentration in $\mathrm{mol} / \mathrm{m}^{3}$, and $\mathrm{S}_{\mathrm{O}}$ the rate of $\mathrm{O}$ in $\mathrm{mol} /\left(\mathrm{sm}^{3}\right)$ produced on the anode side gas phase according to $\left.\left.\mathrm{H}_{2}\right|_{\text {anod }} \rightarrow \mathrm{H}_{2} \mathrm{O}\right|_{\text {anod. }}$. Note that the overall molar density of the fuel gas mixture is given by the ideal gas law.

$$
c=\frac{p}{R T}
$$

Since the oxygen is provided by the cathode, the formation of water from hydrogen is an equimolar conversion and hence $\mathrm{c}$ stays constant even in a closed system. However, the overall mass density $\rho=\mathrm{cM}$, where $\mathrm{M}$ is the molecular weight of the fuel mixture in $\mathrm{kg} / \mathrm{mol}$, might strongly increase between fuel inlet and outlet. In fact, in the extreme case of a pure hydrogen fuel that is completely converted into water, $M$ would increase by a factor of 9 from $2 \times 10^{-3}$ $\mathrm{kg} / \mathrm{mol}$ to $18 \times 10^{-3} \mathrm{~kg} / \mathrm{mol}$. This raises the question if the velocity $w_{\mathrm{i}}$ is affected by this increase in $\rho . \mathrm{w}_{\mathrm{i}}$ and $\rho$ are related to each other through the steady-state overall mass balance, given by

$$
\rho \frac{\partial w_{i}}{\partial x_{i}}+w_{i} \frac{\partial \rho}{\partial x_{i}}=\Pi_{O}
$$

Here, $\Pi_{O}$ in $\mathrm{kg} /\left(\mathrm{sm}^{3}\right)$ denotes the produced mass by $\mathrm{O}^{2-}$ ions reaching the anode through the electrolyte. Since the hydrogen to water conversion is equimolar, both $M$ and $\rho$ increase exactly proportional to the area-specific mass flux $\rho \mathrm{w}_{\mathrm{i}}$. Hence, the divergence of the velocity field $\partial \mathrm{w}_{\mathrm{i}}=\partial \mathrm{x}_{\mathrm{i}}$ vanishes and the overall mass balance becomes

$$
w_{i} \frac{\partial \rho}{\partial x_{i}}=\Pi_{O}
$$

Likewise, Eq. (2) simplifies to

$$
w_{i} \frac{\partial c_{\mathrm{O}}}{\partial \mathrm{x}_{\mathrm{i}}}=\mathrm{S}_{\mathrm{O}}
$$


Note that the left side of Eq. (6) can be transformed from an Eulerian into a Lagrangian reference frame. Using the definition of the material derivative

$$
\frac{\mathrm{D} \Phi}{\mathrm{Dt}}=\frac{\partial \Phi}{\partial t}+w_{i} \frac{\partial \Phi}{\partial x_{i}}
$$

where $\Phi$ can be a scalar or a vector field and $\frac{\partial \Phi}{\partial t}=0$ to account for steady-state conditions, Eq. (6) becomes

$$
\frac{\mathrm{Dc}}{\mathrm{Dt}}=\mathrm{S}_{\mathrm{O}}
$$

Consequently, as shown in Fig. 2, using time $t$ instead of location $\mathrm{x}_{\mathrm{i}}$ as independent variable allows one to interpret Eq. (8) as governing equation for a homogeneous electrochemical reaction taking place in a constant pressure, constant temperature continuous stirred-tank reactor (CSTR). Obviously, the degree of conversion at a given time depends on the kinetics given by $S_{0}$. Also, for a given $S_{0}$, the larger the residence time $\tau$, the larger the degree of conversion.

We proceed further with specifying $\mathrm{S}_{\mathrm{O}}$. Note that with every $\mathrm{O}^{2-}$ ion, two electrons are transferred. Hence the overall electrical current I is related to the overall O-production through Faraday's law

$$
\mathrm{I}=2 \mathrm{~F} \mathrm{~S}_{\mathrm{O}} \mathrm{V}
$$

where $\mathrm{F}=96485 \mathrm{C} / \mathrm{mol}$ is the Faraday constant. Furthermore, $\mathrm{S}_{\mathrm{O}} \mathrm{V}$ is the overall production of $\mathrm{O}$, with $\mathrm{V}$ as the total fuel gas volume provided by the current collector channels. Insertion of Eq. (9) into Eq. (8) gives

$$
\frac{\mathrm{Dc}_{\mathrm{O}}}{\mathrm{D}_{\mathrm{t}}}=\frac{\mathrm{I}}{2 \mathrm{FV}}
$$

The total electrical current can be replaced by

$$
\mathrm{I}=\mathrm{j}_{\mathrm{el}} \mathrm{A}
$$

where $\mathrm{j}_{\mathrm{el}}$ is the local current density and A the total active cell area. As already mentioned, we assume that the local electrochemical behavior follows the characteristic

$$
\mathrm{U}_{\mathrm{L}}=\mathrm{U}_{\mathrm{N}}-\mathrm{ASR}_{\mathrm{RU}} \mathrm{j}_{\mathrm{el}}
$$

where $\mathrm{U}_{\mathrm{L}}$ is the applied external load, $\mathrm{UN}$ is the Nernst voltage and ASRRU is the area-specific internal repeat unit resistance. Insertion of Eqs. (11) and (12) into Eq. (10) then leads to the following electrochemical model 


$$
\frac{\mathrm{Dc}_{\mathrm{O}}}{\mathrm{Dt}}=\frac{\left(\mathrm{U}_{\mathrm{N}}-\mathrm{U}_{\mathrm{L}}\right) \mathrm{A}}{2 \mathrm{~F} \mathrm{ASR}}
$$

Note that for a given load $U_{L}$, the right side of Eq. (13) contains constant parameters only except for the Nernst voltage $U_{N}$ which depends on the logarithm of $c_{0}$. Hence, separation of variables and simple integration of Eq. (13) is not possible. Concerning the further specification of the Nernst voltage for the electrochemical oxidation of hydrogen, one has

$$
\mathrm{U}_{\mathrm{N}}=\frac{\left|\Delta \mathrm{g}_{\mathrm{f}}^{0}(\mathrm{~T})\right|}{2 \mathrm{~F}}+\frac{\mathrm{RT}}{2 \mathrm{~F}} \ln \left(\frac{\mathrm{X}_{\mathrm{H}_{2}} \sqrt{\mathrm{X}_{\mathrm{O}_{2}}}}{\mathrm{X}_{\mathrm{H}_{2} \mathrm{O}}}\right)
$$

where the $\mathrm{X}$ denote the mole fractions of hydrogen and water on the anode and oxygen on the cathode, respectively. According to [Linder 2011], for $\mathrm{T} \geq 373: 15 \mathrm{~K}, \Delta \mathrm{g}_{\mathrm{f}}^{0}(\mathrm{~T})$ in $\mathrm{kJ} / \mathrm{mol}$ is given by

$$
\Delta \mathrm{g}_{\mathrm{f}}^{0}(\mathrm{~T})=-241.2+38.24 \times 10^{-3} \mathrm{~T}+14.15 \times 10^{-6} \mathrm{~T}^{2}-3.722 \times 10^{-9} \mathrm{~T}^{3}
$$

In Eq. (14), we assume the mole fraction of cathodic oxygen to be constant, i.e., $X_{O_{2}} \approx 0.21$. Also, for convenience, we convert the mole fractions of hydrogen and water to molar densities

$$
\mathrm{X}_{\mathrm{H}_{2}}=\frac{\mathrm{c}_{\mathrm{H}_{2}}}{\mathrm{c}}, \quad \mathrm{X}_{\mathrm{H}_{2} \mathrm{O}}=\frac{\mathrm{c}_{\mathrm{H}_{2} \mathrm{O}}}{\mathrm{c}}
$$

where c is given by Eq. (3) and assumed to be constant. Equation (14) then becomes

$$
\mathrm{U}_{\mathrm{N}}=\frac{\left|\Delta \mathrm{g}_{\mathrm{f}}^{0}(\mathrm{~T})\right|}{2 \mathrm{~F}}+\frac{\mathrm{RT}}{2 \mathrm{~F}} \ln \left(\frac{\mathrm{c}_{\mathrm{H}_{2}} \sqrt{0.21}}{\mathrm{c}_{\mathrm{H}_{2} \mathrm{O}}}\right)
$$

To proceed further, we need to relate the ratio $\frac{\mathrm{c}_{\mathrm{H}_{2}}}{\mathrm{c}_{\mathrm{H}_{2} \mathrm{O}}}$ to the elemental oxygen molar density $\mathrm{c}_{\mathrm{O}}$ which is the unknown in Eq. (13). For a hydrocarbon fuel, $\mathrm{c}_{\mathrm{O}}$ is given by

$$
\mathrm{c}_{\mathrm{O}}=\mathrm{c}_{\mathrm{H}_{2} \mathrm{O}}+\mathrm{c}_{\mathrm{CO}}+2 \mathrm{c}_{\mathrm{CO}_{2}}
$$

where we neglected the molar density of anodic oxygen gas, i.e., $c_{02} \approx 0$. Since we assume fuel gas mixtures in local equilibrium, to determine $c_{0}$, standard thermodynamic equilibrium software such as Cantera [Goodwin 2018] could be used. However, this would be somewhat cumbersome since the numerical results of the equilibrium calculations would have to be parameterised and then inserted into Eq. (13). Fortunately, this is not necessary, since an analytical expression of type $\frac{c_{\mathrm{H}_{2}}}{c_{\mathrm{H}_{2} \mathrm{O}}}=f_{e q}\left(c_{O}, \ldots\right)$ can be derived for both pure hydrogen and hydrocarbon fuels. 


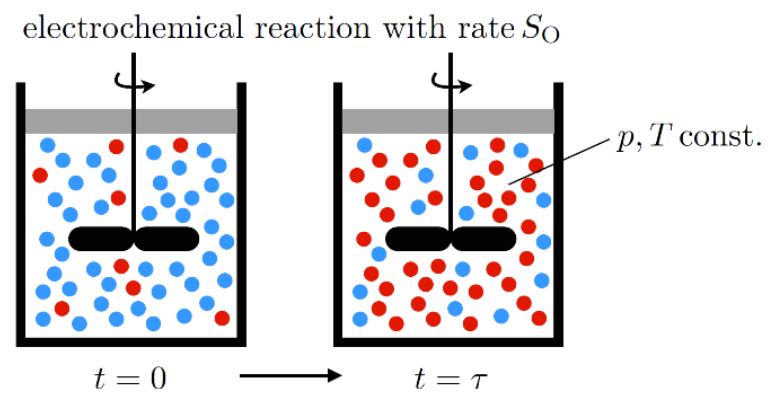

Figure 2: By application of a Lagrangian reference frame, i.e., using time $t$ instead of location $x_{i}$ as independent variable, the electrochemical model governed by Eq. (8) can be represented as a homogeneous electrochemical reaction taking place in a continuous stirred-tank reactor.

\subsection{Electrochemical model applied to hydrogen fuel mixtures}

First, we consider the situation where the fuel consists of a $\left(\mathrm{H}_{2}, \mathrm{H}_{2} \mathrm{O}\right)$ mixture only. In this case, the overall molar density is given by $\mathrm{c}=\mathrm{C}_{\mathrm{H}_{2}}+\mathrm{C}_{\mathrm{H}_{2} \mathrm{O}}$ and Eq. (17) simplifies to

$$
\mathrm{U}_{\mathrm{N}}=\frac{\left|\Delta \mathrm{g}_{\mathrm{f}}^{0}(\mathrm{~T})\right|}{2 \mathrm{~F}}+\frac{\mathrm{RT}}{2 \mathrm{~F}} \ln \left[\left(\frac{\mathrm{c}}{\mathrm{c}_{\mathrm{O}}}-1\right) \sqrt{0.21}\right]
$$

Insertion of Eq. (19) into Eq. (13) then results in

$$
\frac{\mathrm{D}_{\mathrm{c}_{\mathrm{O}}}}{\mathrm{D}_{\mathrm{t}}}=\frac{\mathrm{A}}{2 \mathrm{FASR} \mathrm{RUV}_{\mathrm{V}} \mathrm{V}}\left\{\frac{\left|\Delta \mathrm{g}_{\mathrm{f}}^{0}(\mathrm{~T})\right|}{2 \mathrm{~F}}+\frac{\mathrm{RT}}{2 \mathrm{~F}} \ln \left[\left(\frac{\mathrm{c}}{\mathrm{c}_{\mathrm{O}}}-1\right) \sqrt{0.21}-\mathrm{U}_{\mathrm{L}}\right]\right\}
$$

which can be solved for $c_{0}$ numerically between $t=0$ (inlet) and $t=\tau$ (outlet) by taking into account the given inlet composition $\mathrm{c}_{\mathrm{O}}(0)=\mathrm{c}\left(1-\left.\mathrm{X}_{\mathrm{H} 2}\right|_{\text {in }}\right)$. The corresponding electrical current follows from

$$
I=2 F\left[c_{0}(\tau)-c_{0}(0)\right] \dot{\mathrm{n}} / \mathrm{c}
$$

where the term $\left[\mathrm{c}_{\mathrm{O}}(\tau)-\mathrm{c}_{\mathrm{O}}(0)\right] \mathrm{n} / \mathrm{c}$ represents the total amount of $\mathrm{O}$ in mol/s produced electrochemically. Furthermore, c is given by Eq. (3) and $\dot{n}=\left.\dot{n}_{\mathrm{H}_{2}}\right|_{\text {in }}+\left.\dot{n}_{\mathrm{H}_{2} \mathrm{O}}\right|_{\text {in }}$.

\subsection{Electrochemical model applied to hydrocarbon fuel mixtures}

As mentioned, for hydrocarbon fuel mixtures, it is assumed that the fuel gets completely converted into $\mathrm{H}_{2}, \mathrm{H}_{2} \mathrm{O}, \mathrm{CO}$ and $\mathrm{CO}_{2}$. In addition, suppose the fuel is reformed by catalytic partial oxidation with air, then $\mathrm{N}_{2}$ will be present, but considered to be inert. Therefore, elemental balances only for $\mathrm{O}, \mathrm{C}$, and $\mathrm{H}$ are needed. With $\dot{\mathrm{n}}_{\alpha}$ as the molar flux of species $\alpha$ in $\mathrm{mol} / \mathrm{s}$, one gets

$$
\dot{\mathrm{n}}_{\mathrm{O}}=\dot{\mathrm{n}}_{\mathrm{H}_{2} \mathrm{O}}+\dot{\mathrm{n}}_{\mathrm{CO}}+\dot{\mathrm{n}}_{\mathrm{CO}_{2}}
$$




$$
\begin{gathered}
\dot{\mathrm{n}}_{\mathrm{H}}=2 \dot{\mathrm{n}}_{\mathrm{H}_{2}}+2 \dot{\mathrm{n}}_{\mathrm{H}_{2} \mathrm{O}} \\
\dot{\mathrm{n}}_{\mathrm{C}}=\dot{\mathrm{n}}_{\mathrm{CO}}+\dot{\mathrm{n}}_{\mathrm{CO}_{2}}
\end{gathered}
$$

Furthermore, in Eq. (22), $\dot{\mathrm{n}}_{\mathrm{O}}$ can by replaced by

$$
\dot{\mathrm{n}}_{\mathrm{O}}=\dot{\mathrm{n}} \mathrm{X}_{\mathrm{O}}=\dot{\mathrm{n}} \frac{\mathrm{c}_{\mathrm{O}}}{\mathrm{c}}
$$

with the total molar flux given by

$$
\dot{\mathrm{n}}=\dot{\mathrm{n}}_{\mathrm{H}_{2}}+\dot{\mathrm{n}}_{\mathrm{H}_{2} \mathrm{O}}+\dot{\mathrm{n}}_{\mathrm{CO}}+\dot{\mathrm{n}}_{\mathrm{CO}_{2}}+\dot{\mathrm{n}}_{\mathrm{H}_{2}}
$$

By using Eqs. (22) - (24), Eq. (26) becomes

$$
\dot{\mathrm{n}}=\frac{1}{2} \dot{\mathrm{n}}_{\mathrm{H}}+\dot{\mathrm{n}}_{\mathrm{C}}+\dot{\mathrm{n}}_{\mathrm{H}_{2}}
$$

and therefore, can be derived from the given inlet fuel composition. Equations (22) - (24) contain $\mathrm{n}_{\mathrm{H}_{2}}, \mathrm{n}_{\mathrm{H}_{2} \mathrm{O}}, \mathrm{n}_{\mathrm{CO}}$, and $\mathrm{n}_{\mathrm{CO}_{2}}$ as unknowns. Hence, another equation is required relating them to each other. This relation is given by the law of mass action applied to the water-gas shift reaction

$$
\mathrm{CO}+\mathrm{H}_{2} \mathrm{O} \rightleftharpoons \mathrm{H}_{2}+\mathrm{CO}_{2}
$$

which is assumed to be in equilibrium. We then get

$$
\mathrm{K}_{\mathrm{p}, \mathrm{WGS}}=\frac{\mathrm{p}_{\mathrm{H}_{2}} \mathrm{p}_{\mathrm{CO}_{2}}}{\mathrm{p}_{\mathrm{H}_{2} \mathrm{O}} \mathrm{p}_{\mathrm{CO}}}=\frac{\dot{\mathrm{n}}_{\mathrm{H}_{2}} \dot{\mathrm{n}}_{\mathrm{CO}_{2}}}{\dot{\mathrm{n}}_{\mathrm{H}_{2} \mathrm{O}} \dot{\mathrm{n}}_{\mathrm{CO}}}
$$

where $\mathrm{K}_{\mathrm{p}}$, WGS is the T-dependent equilibrium constant for the water-gas shift reaction. According to [Twigg 1989], $\mathrm{K}_{\mathrm{p}}$, WGS can be expressed empirically as

$$
\mathrm{K}_{\mathrm{p}, \mathrm{WGS}}=\exp \left[0.31688+4.1778 \beta+0.63508 \beta^{2}-0.29358 \beta^{3}\right]
$$

where $\beta \equiv\left(\frac{1000}{T}-1\right)$ with T in K. Equations (22) - (24) in combination with Eq. (29) can be solved analytically using e. g. Mathematica [Wolfram Research 2018]. The result is quite lengthy and will be shown only in a formal way as

$$
\frac{\mathrm{c}_{\mathrm{H}_{2}}}{\mathrm{c}_{\mathrm{H}_{2} \mathrm{O}}}=\mathrm{f}_{\mathrm{eq}}\left(\mathrm{c}_{\mathrm{O}}, \mathrm{c}, \mathrm{K}_{\mathrm{p}, \mathrm{WGS}}, \dot{\mathrm{n}}_{\mathrm{C}}, \dot{\mathrm{n}}_{\mathrm{H}}, \dot{\mathrm{n}}_{\mathrm{N}_{2}}\right)
$$


When inserted into Eq. (17) and subsequently into Eq. (13), we obtain

$$
\frac{\mathrm{D}_{\mathrm{c}_{\mathrm{O}}}}{\mathrm{D}_{\mathrm{t}}}=\frac{\mathrm{A}}{2 \mathrm{FASR} \mathrm{RUV}_{\mathrm{R}} \mathrm{V}}\left\{\frac{\left|\Delta \mathrm{g}_{\mathrm{f}}^{0}(\mathrm{~T})\right|}{2 \mathrm{~F}}+\frac{\mathrm{RT}}{2 \mathrm{~F}} \ln \left[\mathrm{f}_{\mathrm{eq}}\left(\mathrm{c}_{\mathrm{O}}, \ldots\right) \sqrt{0.21}\right]-\mathrm{U}_{\mathrm{L}}\right\}
$$

Eq. (32) can be solved for $\mathrm{c}_{0}$ numerically between $\mathrm{t}=0$ (inlet) and $\mathrm{t}=\tau$ (outlet) by taking into account the given inlet composition $\mathrm{c}_{\mathrm{O}}(0)=\left.2 \mathrm{n}_{\mathrm{O} 2}\right|_{\text {in }} \mathrm{c} / \dot{\mathrm{n}}$. The corresponding electrical current follows from Eq. (21), where $\mathrm{c}$ is given by Eq. (3) and $\mathrm{n}_{-}$by Eq. (27).

\subsection{Current collector design, 3D CFD model and extracted residence times}

The electrochemical model described above uses the residence time $\tau$ of a certain fuel flow path as input to calculate for a given external load the corresponding production of $\mathrm{O}$. As shown in Fig. 3, current collectors used in SOFC stacks typically consist of a rather complex arrangement of flow channels for gas distribution and ribs for both current collection and current distribution. In the shown design, the fuel enters from the center (green line) and leaves at the outside (red lines). To calculate the residence time distribution (RTD) for a given fuel flow rate and temperature, the required velocity field was obtained from solving the 3D steadystate Navier-Stokes equations in ANSYS CFX [ANSYS 2018]. Since realistic fuel flow rates always stayed within the laminar flow regime, no turbulence model was required. Also, since the temperature was assumed to be constant, solving the energy balance was not required either. Furthermore, since the pressure drop between inlet and outlet was always below $100 \mathrm{~Pa}$, an incompressible fluid solver would have been sufficient. However, a compressible fluid solver was used with the overall density related to the overall pressure through the ideal gas law. Finally, the fluid viscosity was assumed to be constant. It was calculated based on the equilibrated inlet fuel composition and the pure-component viscosities using a simple mixing rule based on the mass fractions of the involved chemical species. This rather crude approach was considered to be sufficient. However, variable, composition-dependent viscosities could be included as an extension to the presented model.

As for the calculation of residence times along different flow paths between inlet and outlet, we defined the ANSYS CFX variable restime, subject to the transport equation $\frac{D_{\text {restime }}}{\mathrm{Dt}}=1$. Restime was then integrated along different flow paths to obtain the corresponding $\tau$-values. In addition, calculating the overall (I-U)-behavior from a given RTD requires knowledge of the volumetric flow rate $\dot{V}_{\alpha}$ associated with a specific residence time $\tau_{\alpha}$. For this, the corresponding surface elements $A_{\alpha, i}$ at the outlet and associated local velocities $w_{\alpha, i}$ were used to calculate the volumetric fluxes

$$
\mathrm{V}_{\alpha}\left(\tau_{\alpha}\right)=\mathrm{A}_{\alpha, \mathrm{i}} \mathrm{w}_{\alpha, \mathrm{i}}, \quad \alpha=1 \ldots \alpha_{\max }
$$

Finally, for a repeat unit with a current collector similar to that shown in Fig. 3, to calculate the overall electrical current for a specific external load $U_{L}$, the following procedure was applied: 


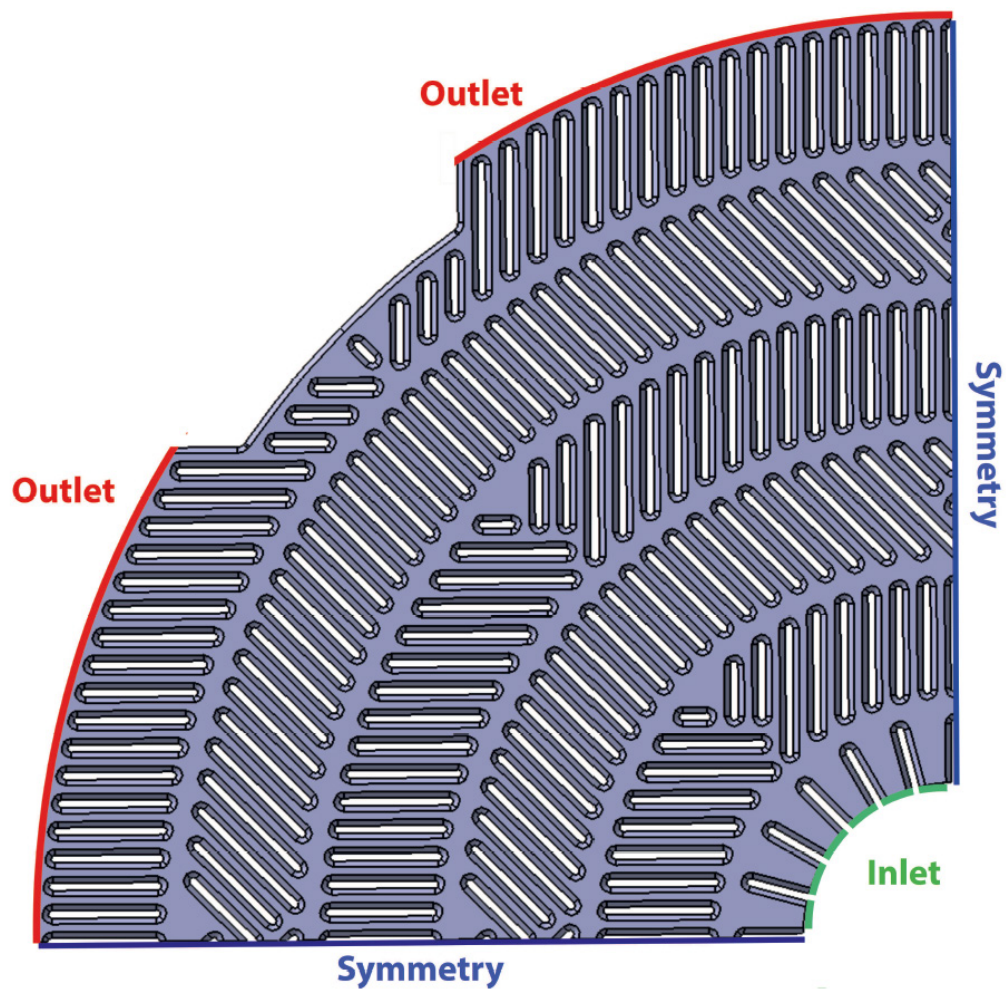

Figure 3: Top view on the anode side of a quarter of a HEXIS current collector plate. The flow channels are shown in grey whereas the ribs are shown in white. For a typical SOFC repeat unit operation at $850^{\circ} \mathrm{C}$ on $4: 01 \mathrm{~g} / \mathrm{h}$ CPO-reformed natural gas with an air-to-fuel ratio of $\lambda=0: 26$, the corresponding residence time distribution between inlet (green line) and outlet (red lines) is shown in Fig. 9.

Finally, for a repeat unit with a current collector similar to that shown in Fig. 3, to calculate the overall electrical current for a specific external load $U_{L}$, the following procedure was applied:

1. Determine the RTD from 3D CFD data, i.e., $\tau_{\alpha}$-values and corresponding volumetric fluxes $\dot{\mathrm{V}}_{\alpha}$ for $\alpha=1 \ldots \alpha_{\max }$

2. Solve either Eq. (20) for hydrogen fuels or Eq. (32) for hydrocarbon fuels up to the largest residence time_max. For this, i.e., the internal resistance $\mathrm{ASR}_{\mathrm{RU}}$ needs to be known either from electrochemical impedance spectroscopy (EIS) data or by fitting the model to experimental (I-U) data, see [Linder 2015] for details

3. For each residence time $\tau_{\alpha}$, calculate the corresponding electrical current $I_{\alpha}$ by using Eq. (21)

4. 4. Calculate the overall current from $I=\sum_{\alpha=1}^{\alpha \max } I_{\alpha} \dot{V}_{\alpha}$ and the overall current density from $\mathrm{j}_{\mathrm{el}}=\mathrm{I} / \mathrm{A}$, where $\mathrm{A}$ is the active cell area 
As discussed in the following section, by repeating steps 1 to 4 for varying loads, the (I-U) behavior can be computed as a function of the gas channel geometry, the inlet fuel mass flux and composition as well as the operating temperature.

\section{RESULTS}

3.1. Results for hydrogen fuel mixtures

Figure 4 shows typical results for the oxygen molar density $c_{0}(t)$ as obtained from Eq. (20). Note that for external loads close to the Nernst voltage, the source term in Eq. (20) approaches zero and consequently $\mathrm{c}_{\mathrm{O}}(\mathrm{t}) \approx \mathrm{c}_{\mathrm{O}} \mathrm{l}_{\text {in }}=$ const. In contrast, for $\mathrm{U}_{\mathrm{L}} \rightarrow 0, \mathrm{c}_{\mathrm{O}}(\mathrm{t})$ approaches its maximum value, which depends on the amount of available $\mathrm{H} 2$. However, it turns out that $\max \left(c_{0}\right)$ is slightly smaller than the theoretical maximum given by a complete conversion of the hydrogen fuel, i.e., $c=p /(R T)$. This can be explained by the RT $\ln (\ldots)$ term in the Nernst equation which represents the entropy change associated with the electrochemical conversion of hydrogen to water. Entropically, it is impossible to have a complete electrochemical conversion. Even though differences between $\max \left(\mathrm{c}_{0}\right)$ and $\mathrm{c}$ are small, they increases with increasing operation temperature.

Figure 5 presents artificial RTDs for four different repeat units all fueled with the same hydrogen flux. Fig. 5-a shows a Gaussian distribution around 0:49 s, Fig. 5-b a unimodal residence time of $1 \mathrm{~s}$, Fig. 5-c a descending distribution with 0:49 $\mathrm{s}$ as the smallest residence time and Fig. 5-d a unimodal residence time of 0.49 s. In Figs. 6 and 7, the corresponding (I-U) curves are shown for two different internal resistances. Note that the magnitudes of the chosen residence times are much larger than those typical for SOFC stacks but are convenient to explain the impact of the shape of the RTD on the resulting (I-U) curves. In Fig. 6, ASR $\mathrm{RU}=$ $0.25 \Omega \mathrm{cm}^{2}$, which is a typical startup value for SOFC repeat units - without any negative power losses by ageing effects. One sees that all four RTDs lead to rather similar (I-U) curves. At a closer look, one notices that RTD-a has the lowest and RTD-b the highest performance. This is caused by the fact that RTD-b has a residence time about twice as large as the average value of RTD-a. RTD-d is slightly better than RTD-a and RTD-c slightly better than RTD-d. These differences become much more pronounced when the internal resistance is rather drastically increased to $\mathrm{ASR}_{\mathrm{RU}}=0.80 \Omega \mathrm{cm}^{2}$, which corresponds to a degraded SOFC repeat unit. RTD-b now leads to a much better performance than the other RTDs. Only RTD-c performs similarly well for $\mathrm{j}_{\mathrm{el}}<0.22 \mathrm{~A} / \mathrm{cm}^{2}$. At a closer look, one notices that the inferior performance of RTD-c at higher currents is caused by its smallest residence time of $0.49 \mathrm{~s}$. A similar behaviour can be observed when comparing RTD-a with RTD-d. Since RTD-a consists of residence times below $0.49 \mathrm{~s}$, this causes the associated (I-U) curve to exhibit an inferior performance at high current densities.

Note also that comparison of RTD-a with RTD-d and RTD-b with RTD-c shows that for the same average residence time, a broadening of the RTD generally leads to a decrease in performance. Broad RTDs with a large share in small residence times are harmful at high internal resistances and high current densities and therefore should be avoided. This is especially significant when a SOFC stack needs to be optimized for life-times in the range of 10 years where rather strong long-time degradation is unavoidable. 


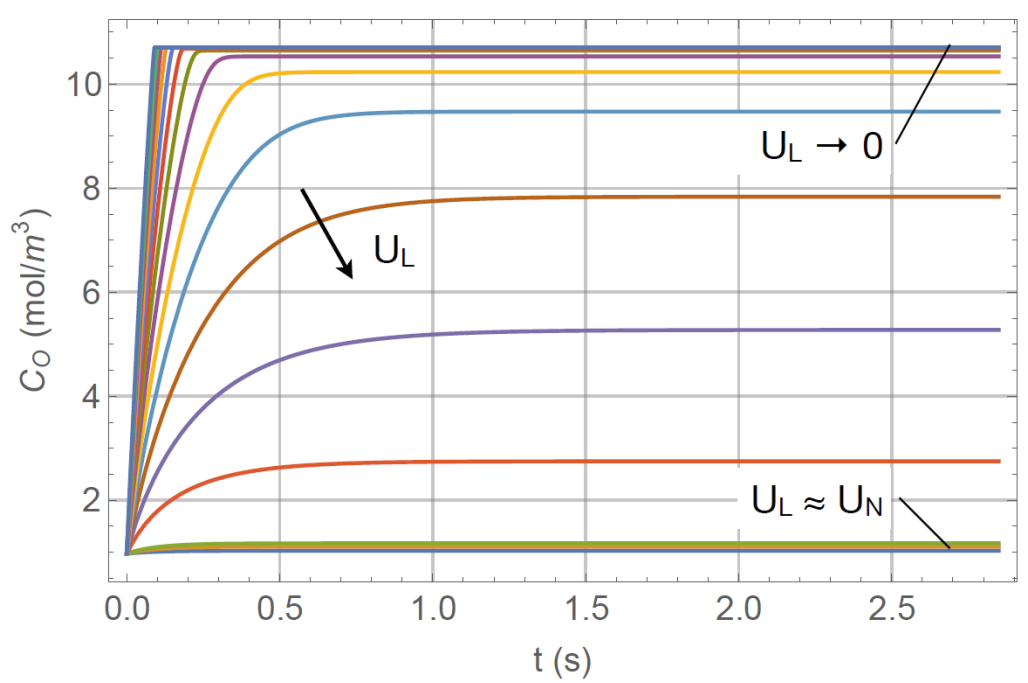

Figure 4: Typical solution of Eq. (20) for the time-dependent oxygen molar density $c_{0}(t)$ for several external loads $U_{L}$ between the Nernst voltage $U_{N}$ and $U_{L} \rightarrow 0$. The highly nonlinear behaviour of $c_{0}(t)$ is a consequence of $U_{N}\left(c_{0}\right)$ as given by Eq. (19).
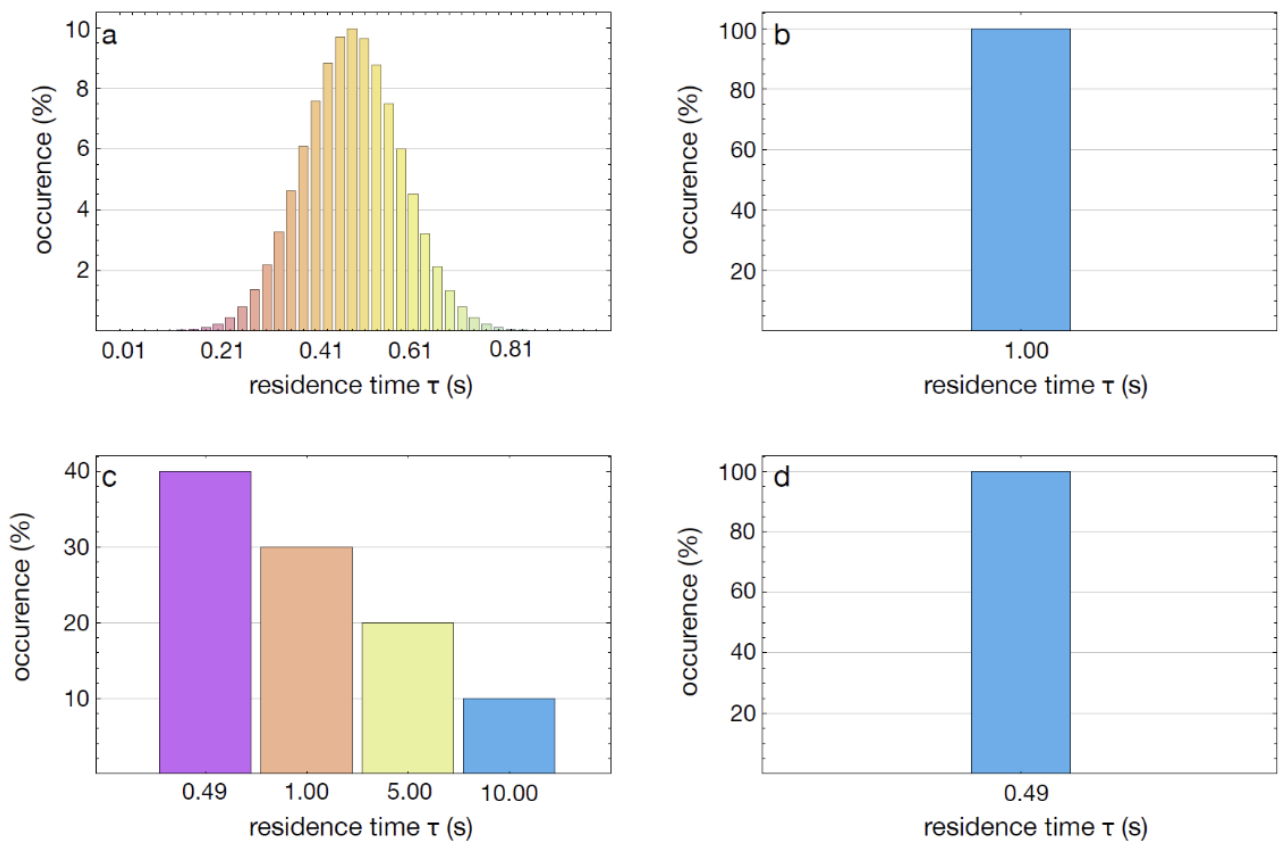

Figure 5: Artificial residence time distributions for four different repeat units all fueled with the same hydrogen flux. (a) represents a Gaussian distribution around 0:49 s, (b) and (d) unimodal residence times of $1 \mathrm{~s}$ and 0:49 s, respectively, and (c) a descending distribution with 0:49 $\mathrm{s}$ as the smallest residence time. 


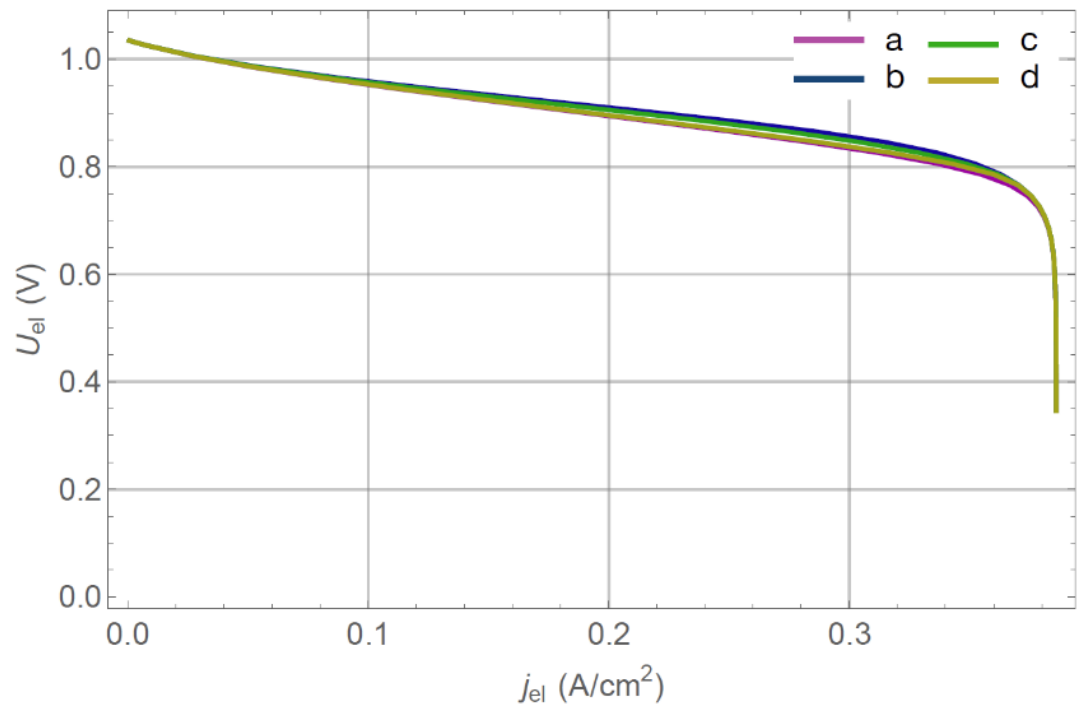

Figure 6: Current voltage curves predicted from Eqs. (20) and (21) for an internal resistance of $\mathrm{ASR}_{\mathrm{RU}}=0.25 \Omega \mathrm{cm}^{2}$ for the four different residence time distributions shown in Fig. 5. Curve (a) is based on a Gaussian distribution around 0.49s, (b) and (d) on unimodal residence times of $1 \mathrm{~s}$ and $0.49 \mathrm{~s}$, respectively, and (c) on a descending distribution with 0.49 s as the smallest residence time.

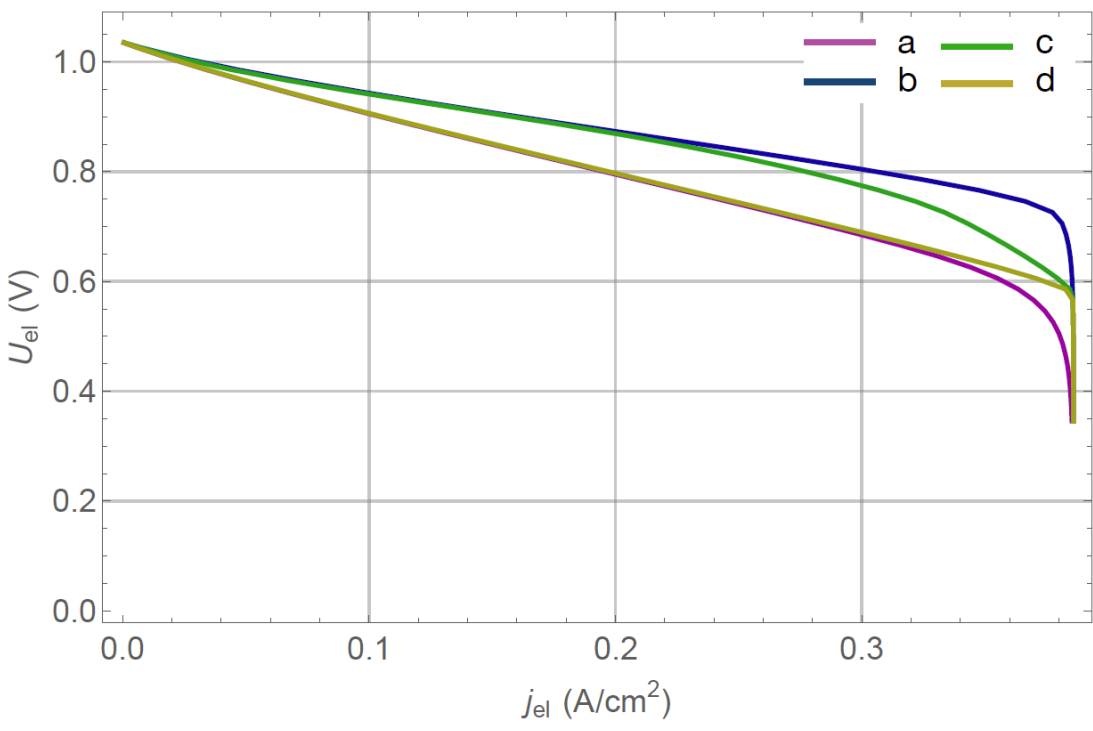

Figure 7: Current voltage curves predicted from Eqs. (20) and (21) for an internal resistance of $\mathrm{ASR}_{\mathrm{RU}}=0.80 \Omega \mathrm{cm}^{2}$ for the four different residence time distributions shown in Fig. 5. Curve (a) is based on a Gaussian distribution around $0.49 \mathrm{~s}$, (b) and (d) on unimodal residence times of $1 \mathrm{~s}$ and $0.49 \mathrm{~s}$, respectively, and (c) on a descending distribution with 0.49 s as the smallest residence time. 


\subsection{Results for hydrocarbon fuel mixtures}

Figure 8 shows a comparison between our model and that of [Linder 2015]. Here, the SOFC repeat unit operates at $900^{\circ} \mathrm{C}$ and is fueled by $4 \mathrm{~g} / \mathrm{h}$ CPO-reformed pure methane with an airto-fuel ratio of $\lambda=0: 27$. Since the model by Linder et al. assumes an average residence time of $\tau_{\text {ave }}=\frac{\mathrm{v}}{\dot{\mathrm{V}}}$, we as well evaluated our model for a single residence time of $\tau_{\text {ave }}=0.177 \mathrm{~s}$. One sees that there is almost perfect agreement between the two models. The small differences seen probably are caused by small differences in the numerical values for $\mathrm{K}_{\mathrm{p}, \mathrm{WGS}}$.

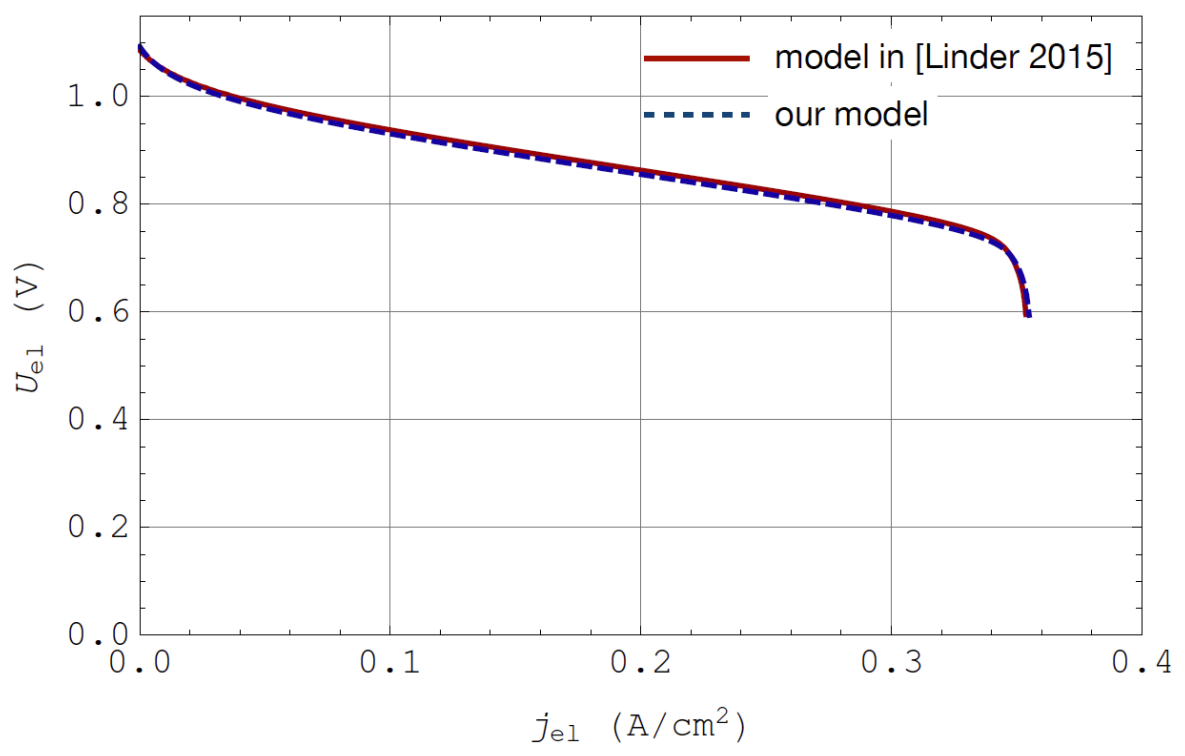

Figure 8: Comparison of our model as given by Eq. (32) for a single residence time of $\tau_{\text {ave }}=0.177 \mathrm{~s}$ with that of [Linder 2015] for a SOFC repeat unit operated at $900^{\circ} \mathrm{C}$ running on $4 \mathrm{~g} / \mathrm{h}$ CPO-reformed pure methane with an air-to-fuel ratio of $\lambda=0: 27$.

For a validation against experimental data, we compared our model with an (I-U) curve obtained from a HEXIS repeat unit. The repeat unit was operated at $850^{\circ} \mathrm{C}$ on $4: 01 \mathrm{~g} / \mathrm{h} \mathrm{CPO}-$ reformed natural gas with an air-to-fuel ratio of $\lambda=0: 26$. First, residence times and corresponding volumetric fluxes were calculated from 3 D CFD simulation data. The results are shown in Fig. 9. One sees that the RTD has its maximum peak at $\tau \approx 0.09 \mathrm{~s}$. Then, there is a rather steep descent towards the smallest residence time of about $0.08 \mathrm{~s}$. In contrast, for residence times above $0.09 \mathrm{~s}$, the distribution gets much broader and has its maximum value at around $0.3 \mathrm{~s}$. However, those high residence times have very low associated volume fluxes. The corresponding (I-U) curve is shown in Fig. 10 in comparison with the experimental (I-U) curve. For this comparison, the model had to be adjusted. Firstly, the nominal fuel composition had to be pre-oxidized to account for leakage losses so that both open circuit voltages match. Secondly, the internal repeat unit resistance, $\mathrm{ASR}_{\mathrm{RU}}$, assumed to be constant by the model, was adjusted to match the slope of the experimental curve at small to intermediate current densities. Note that $A_{R U}$ was the only fit parameter used. As shown by [Linder 2015], $A_{R R_{R U}}$ values obtained by fitting their model to experimental (I-U) curves agreed well with the values 
extracted from electrochemical impedance spectroscopy (EIS) data. Using our model, we as well obtained a realistic $\mathrm{ASR}_{\mathrm{RU}}$ value that agreed well with corresponding EIS data. With these adjustments, we obtained excellent agreement up to current densities of $0.25 \mathrm{~A} / \mathrm{cm}^{2}$. For higher current densities, the agreement is much less satisfying. The stronger bending of the experimental (I-U) curve at high current densities could be caused by: (i) axial diffusion effects (not accounted for by the model) that would further broaden the RTD shown in Fig. 9 and/or (ii) limitations of the rather simple electrochemical model that we use such as a currentdependent $\mathrm{ASR}_{\mathrm{RU}}$ (that was assumed to be constant) close to the maximum current.

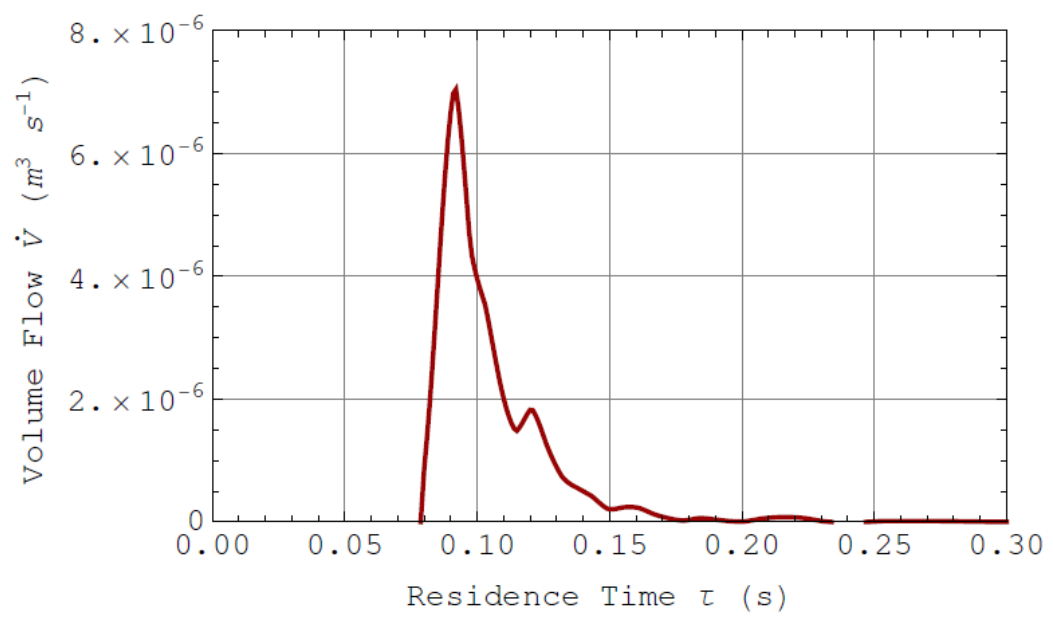

Figure 9: Residence time distribution obtained from CFD flow simulations of the fuel gas side of a HEXIS SOFC repeat unit running at $850^{\circ} \mathrm{C}$ on $4: 01 \mathrm{~g} / \mathrm{h}$ CPOreformed natural gas with an air-to-fuel ratio of $\lambda=0: 26$.

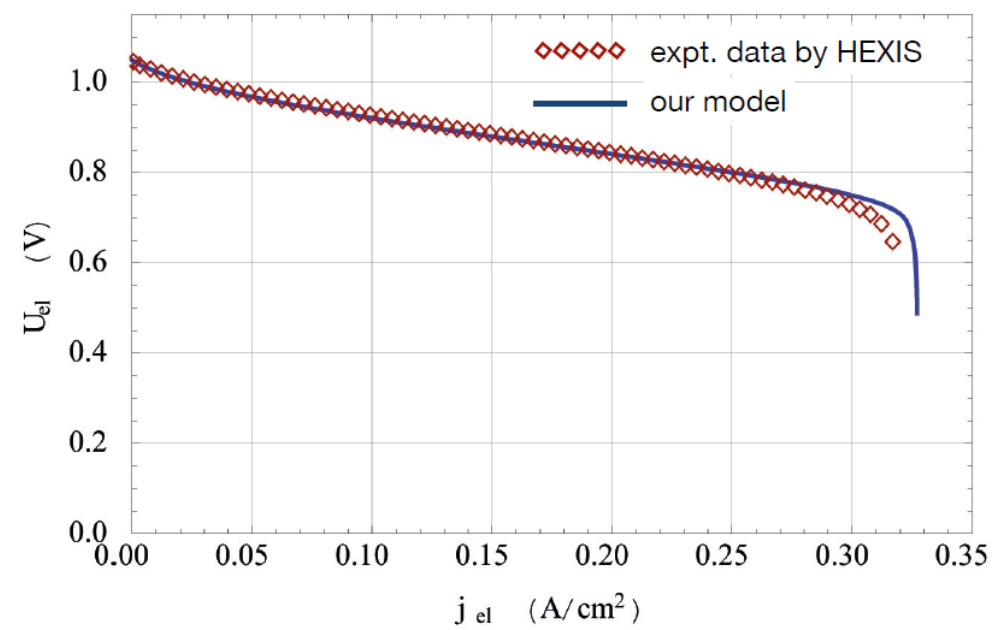

Figure 10: Comparison of our model as given by Eq. (32) for the residence time distribution shown in Fig. 9 with experimental data from a HEXIS SOFC repeat unit running at $850^{\circ} \mathrm{C}$ on $4: 01 \mathrm{~g} / \mathrm{h}$ CPO-reformed natural gas with an air-to-fuel ratio of $\lambda=0: 26$. 


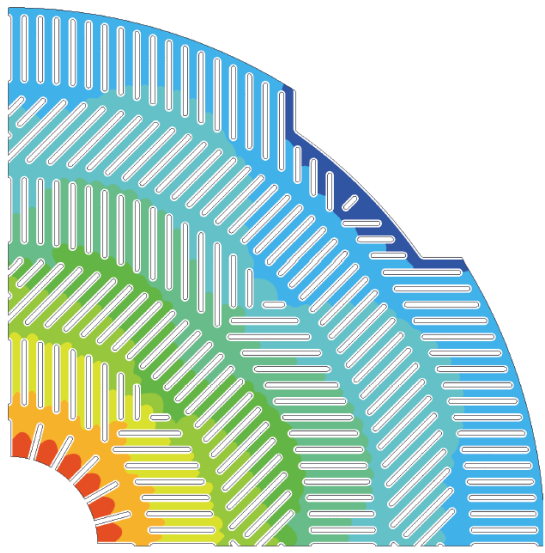

$U_{L}=0.9 \mathrm{~V}$

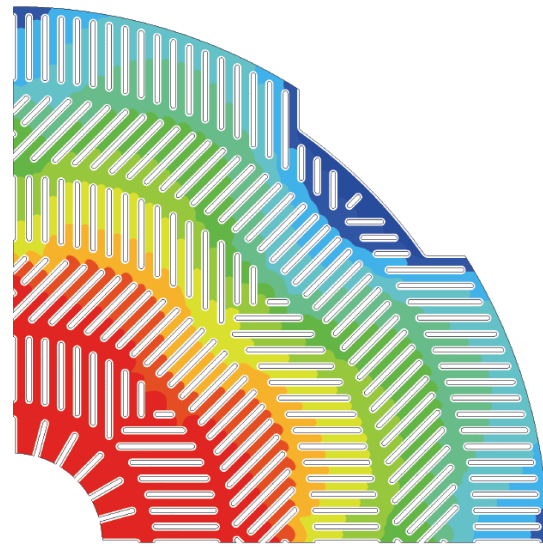

high

$U_{L}=0.8 \mathrm{~V}$

Figure 11: Current density distributions in a quarter of a HEXIS current collector plate for electrical loads of $\mathrm{U}_{\mathrm{L}}=0: 9 \mathrm{~V}$ and $0: 8 \mathrm{~V}$, respectively. The results were obtained from Eq. (32) for the residence time distribution shown in Fig. 9.

The presented model not only predicts the overall (I-U) behaviour of SOFC repeat units, but also is very useful for assessing the local fuel gas and current density distributions. As an example, Fig. 11 shows the local current densities in a quarter of a HEXIS current collector plate for two different electrical loads. For $\mathrm{U}_{\mathrm{L}}=0.8 \mathrm{~V}$, the overall electrical current must be larger than for $0.9 \mathrm{~V}$. Indeed, when the load is lowered, the region in red indicating the highest current densities extends from the inner radius towards the center of the current collector. Note also that the smallest current densities occur at the outer radius in between the two outlets, see also Fig. 3.

\section{SUMMARY}

The presented model framework allows one to calculate the (I-U) characteristics of a solid oxide fuel cell repeat unit that runs on both hydrogen and hydrocarbon fuel mixtures. The model uses as input residence times obtained from 3D CFD data for the fuel flowing through the anodic gas channels of a current collector plate. These residence times are then used by an electrochemical model to predict the fuel conversion along different flow paths for various electrical loads. When combined, they give the overall (I-U) curve of the repeat unit. In Fig. 7, the results for hydrogen fuels show how the smallest residence times lower the electrochemical performance. The results also show that for the same average residence time, broader RTDs lead to a decrease in performance. This is relevant for high fuel utilizations and high internal resistances in the range of $\mathrm{ASR}_{\mathrm{RU}}=0.80 \Omega \mathrm{cm}^{2}$ typical for aged SOFC stacks.

With respect to the modelling of hydrocarbon fuels, our model perfectly reproduced that of [Linder 2015] for CPO-reformed pure methane assuming a single residence time $\tau_{\text {ave }}$, see Fig. 8 . Furthermore, for current densities of about $0.25 \mathrm{~A} / \mathrm{cm}^{2}$, it agreed well with experimental (I$\mathrm{U})$ obtained for a HEXIS repeat unit running on CPO reformed natural gas, see Fig. 10. For higher current densities, the agreement is much less satisfying. We attributed this to axial diffusion effects that would lead to smaller (and larger) residence times and/or limitations of the electrochemical model such as the $\mathrm{ASR}_{\mathrm{RU}}$ assumed to be constant. This assumption might break down close to the maximum current. 
Finally, the presented model is very useful for assessing the local fuel gas and current density distributions over a SOCF repeat unit. This was demonstrated in Fig. 11, where the change in local current densities with the external load was discussed. Knowledge about the local conditions of the repeat unit allows one, for example, to investigate degradation phenomena in button cell experiments under realistic conditions by adjusting the fuel composition and electrical current according to those predicted by our model. Fortunately, these types of analyses can be performed in a highly efficient and robust manner: solving the Navier-Stokes equations, extracting the corresponding RTD from the velocity field, solving Eq. (32) in combination with Eq. (21) is all that is needed. Note also that the presented model is flexible enough to be improved and extended in several different directions. It could be expanded, e.g., to simulate the gas conversion impedances for hydrocarbon fuels at different utilizations which would greatly help interpreting experimental (I-U) data. Also, the consumption of oxygen on the cathode and axial diffusion effects could be included.

\section{ACKNOWLEDGEMENTS}

The authors would like to thank Dr. Lorenz Holzer for carefully revising the manuscript and for his suggestions for improvement. Also, we would like to thank HEXIS AG Winterthur (Switzerland) and the Swiss Federal Office of Energy (SFOE) for their support within the Fermi project.

\section{DEDICATION}

This publication is dedicated to *my father Karl-Heinz Hocker, who passed away during the preparation of the manuscript on October 25, 2018.

\section{REFERENCES}

[1] [Kendall 2016] K. Kendall and M. Kendall, High-Temperature Solid Oxide Fuel Cells for the 21st Century: Fundamentals, Design and Applications, Elsevier Science (2016).

[2] [Mai 2013] A. Mai, B. Iwanschitz, J. A. Schuler, R. Denzler, V. Nerlich, A. Schuler, "HEXIS' SOFC System Galileo $1000 \mathrm{~N}$ - Lab and Field Test Experiences", ECS Transactions, 57, pp. 73-80 (2013).

[3] [Schulze 2007] M. Schulze, E. Gülzow, St. Schönbauer, T. Knöri, R. Reissner, "Segmented cells as tool for development of fuel cells and error prevention/prediagnostic in fuel cell stacks", Journal of Power Sources, 173, pp. 19-27 (2007).

[4] [Wuillemin 2009] Z. Wuillemin, A. Nakajo, A. Müller, A. Schuler, S. Diethelm, J. Van Herle, D. Favrat, "Locally-Resolved Study of Degradation in a SOFC RepeatElement", ECS Transactions, 25, pp. 457-466 (2009).

[5] [Bessler 2010] W. G. Bessler S. Gewies C. Willich G. Schiller K. A. Friedrich, "Spatial Distribution of Electrochemical Performance in a Segmented SOFC: A Combined Modeling and Experimental Study”, Fuel Cells, 10, pp. 411-418 (2010).

[6] [Janardhanan 2006] V. M. Janardhanan, O. Deutschmann, "CFD analysis of a solid oxide fuel cell with internal reforming: Coupled interactions of transport, hetero- geneous catalysis and electrochemical processes", Journal of Power Sources, 162, pp. 11921202 (2006). 
[7] [Schumacher 2012] J. O. Schumacher, J. Eller, G. Sartoris, T. Colinart, B. C. Seyfang, " $2+1 \mathrm{D}$ modelling of a polymer electrolyte fuel cell with glassy-carbon microstructures", Mathematical and Computer Modelling of Dynamical Systems, 18, pp. 355-377 (2012).

[8] [Sang-Keun 2016] D. Sang-Keun, J. Woo-Nam, R. Kashif, K. Akiyoshi, "Design and numerical analysis of a planar anode-supported SOFC stack", Renewable Energy, 94, pp. 637-650 (2016).

[9] [Linder 2015] M. Linder, T. Hocker, C. Meier, L. Holzer, K. A. Friedrich, B. Iwanschitz, A. Mai, J. A. Schuler, “A model-based approach for current voltage analyses to quantify degradation and fuel distribution in solid oxide fuel cell stacks", Journal of Power Sources, 288, pp. 409-418 (2015).

[10] [Linder 2011] M. Linder, T. Hocker, R. Denzler, A. Mai, B. Iwanschitz, "Automated, Model-Based Analysis of Uj-Data for Electrolyte-Supported SOFC Short-Stacks", Fuel Cells, 11, pp. 573-580 (2011).

[11] [Goodwin 2018] D. G. Goodwin, H. K. Moffat, and R. L. Speth. Cantera: An objectori- ented software toolkit for chemical kinetics, thermodynamics, and transport processes http://www.cantera.org (2018).

[12] [Twigg 1989] M. V. Twigg, Catalyst Handbook, second edition, Wolfe Publishing Ltd. (1989).

[13] [Wolfram Research 2018] Wolfram Research Inc., Mathematica, Version 11.2, Champaign, IL (2018).

[14] [ANSYS 2018] ANSYS Inc., ANSYS CFX Release 18, Canonsburg, PA (2018). 
